\title{
Da Farmácia Galénica à Farmácia Química no Portugal Setecentista
}

\section{Introdução}

1.1 - Com a introdução da Inquisição em Portugal, em 1536, e com a perda da independência nacional em favor da coroa de Espanha, em 1580, seguida, até meados do século XVII, pelas lutas patrióticas de reconquista e solidificação da mesma, passaram a ser pouquíssimos os portugueses que deixavam a pátria para irem estagiar e aprofundar os seus conhecimentos nos grandes centros europeus. E passaram a ser pou$\cos$, ou mesmo nenhuns, os mestres estrangeiros que eram contratados para ensinarem em Portugal. Os poucos contactos que restavam aos estudiosos portugueses eram com a vizinha Espanha, também ela fechada e separada das ideias estrangeiras.

Com a Inquisição veio o primeiro Índice dos Livros Proibidos, em 1551, periodicamente acrescentado. Com ela vieram também os autos-de-fé, a morte e a confiscação dos bens para aqueles que introduzissem ou fizessem circular livros sem as necessárias licenças, ou fossem de algum modo suspeitos de menos ortodoxia. Em particular, a insegurança e o medo instalaram-se entre os mestres de origem judaica, com lugar de relevo nos diversos domínios da cultura portuguesa. Sempre receosos da prisão e possível condenação, muitos deles abandonaram, pura e simplesmente, o país. Com a perda da independência em favor da coroa espanhola, a acção governativa dos Filipes e as lutas da Restauração que se lhe seguiram foram ruinosas para a eficaz protecção e desenvolvimento da Instrução Pública.

Logo em 1583, Filipe II de Espanha, Filipe I em Portugal, nomeou um visitador e reformador da Universidade, Manuel Quadros, encarregando-o de construção de novos edifícios e da elaboração de novos estatutos. Estes seriam confirmados por carta régia de 18 de Outubro de 1591 e viriam a ser reformados, sem diferenças significativas em aspectos relevantes, seis anos mais tarde, e re-confirmados em 1654, após a restauração nacional.

$\mathrm{Na}$ Universidade que estes estatutos regiam, pontificaram, até meados do século XVIII, os jesuitas. O ensino que aí ministravam era feito da leitura e comentário dos mestres da Escolástica, dogmaticamente orientado pela filosofia peripatética. Muitos deles tornaram-se famosos, no país e fora dele, conhecidos por os Conimbricenses. Os Commentaria Collegii Conimbrincensis in Universam Dialecticam Aristotelis Stagyritae de Sebastião do Couto (1), os Cursus Philosophicus de Francisco Suarez (2), ou o Cursus Philosophicus Conimbricensis de António Cordeiro (3), dão-nos bem conta do conteúdo desse ensino.

Na Faculdade de Medicina de Coimbra do século XVII liam-se os livros de Galeno, Avicena, Razi, Aristóteles,
Hipócrates, Mesua, quer no estudo da Anatomia, quer no estudo dos simples, drogas, especiarias, venenos e outras mezinhas, nas suas propriedades e qualidades químicas, servindo-se de princípios e técnicas químicas. Necessariamente, os médicos dela saídos pertenciam à seita médica dos dogmáticos, fiéis à doutrina de Galeno e Hipócrates que na acção dos contrários e na Teoria dos Humores buscam o principio de toda a cura. Com pequenos reparos a outras influências, esta é a orientação de fundo dos escritos de autores portugueses, ao longo do século XVII, no domínio da medicina, nomeadamente das obras de João Bravo Chamisso De Medendis Corporis Malis per Manualem Operationem (4), Gerónimo Nunes Ramirez Commentaria in Librum Galeni (5), Gonçalo Rodrigues Cabreira Compêndio de muitos e Varios Remédios, de Cirurgia, e outras cousas curiosas (6), André António de Castro De Febrium Curatione Lib. 3; De simplicium medicamentorum Lib. 2; De qualitatibus alimentorum quae humani corporis nutritioni sunt apta Tract. 10 (7), Duarte Madeira Arrais Methodo de conhecer $e$ curar o Morbo Gallico (8) e Novae Philosophiae et Medicinae de Qualitatibus Occultis a Nemine unquam Excultae (9), António Cruz Recompilaçam de Cirurgia (10), Gabriel Grisley Desengano para a Medicina ou Botica para todo o Pay de Familias (11), Manoel de Azevedo Correç̧ão e Abusos contra o Verdadeiro Methodo de Medicina (12) e Thome Rodrigues da Veiga Pratica Medica (13), este último editado oitenta e nove anos depois da morte de seu autor.

$\mathrm{Na}$ obra de Duarte Pereira Arrais é todavia, clara e patente a influência de J. Duchesne e Sennert. Nela são abundantes as referências a estes autores, como o são as citaçð̄es de L. Fioravanti, Kircher e Fernel. Inclusive, nele encontramos a primeira referência, em português, a Paracelso no Methodo de conhecer $e$ curar o Morbo Gállico, (Quest. XXXVII, Art. ${ }^{\circ} 1$, pg. 503), ao tratar da possível cura do morbo gálico com azougue aplicado por fora ou por dentro, aduzindo em favor da doutrina que expðe, entre outros, Fernel, Fallopio, Theophrasto Paracelso, Aquitano, Hutenc e João Baptista Montano. A citação referente a Paracelso remete para o Lib. 8 , cp. 1 que não corresponde a nada nas ediçס̄es das obras de Paracelso Operum Medico-Chimicorum (Francofurti, 1603-1605) ou Operum Latine Redditorum (Basileae, 1575), tratando-se, possivelmente, duma citação em segunda mão. Anteriormente ao escrito de Duarte Arrais em que se encontra a referida citação de Paracelso, Estevão Rodrigues de Castro, por alguns autores designado a Phoenix da Medicina Portuguesa, terá sido convicto discípulo de

a Departamento de Química - Universidade 3000 Coimbra. 
Paracelso (14); de notar, todavia, que o ensino deste médico português se exerceu sempre fora do país e as suas obras, também publicadas fora de Portugal, foram escritas em latim.

A doutrina de Athanasius Kircher sobre a arte magnética não é para Duarte Arrais mais que uma doutrina "satis curiosum» (ref. 9, Disp. IX, sect. 1) que não chega a convencê-lo; e a tese de Sennert sobre a natureza atómica das coisas é por ele rotundamente refutada, baseando-se em Avicena e no Curso Philosophico dos Conimbricenses (ref. 9, Disp. II, sect. VI). Mostra-se, todavia, favorável ao uso do antimónio, referindo que pelo fogo se pode reduzir a sua violência «tornando-o tão benigno que até se pode dar às crianças» (ref. 8, Quest. XXVIII, Art. I) afastando-se assim do arsenal terapêutico estrito da farmácia galénica, constituído, tradicionalmente e na generalidade, por substâncias de origem animal e vegetal; e decidiu-se a escrever na língua vulgar sobre assunto a que parecia ser mais acomodada a lingua latina, dizendo imitar «os gregos, árabes e outros que nas suas linguas vulgares escreveram todas as sciências, pois dellas não há língua próprian" (ref. 8, Prólogo).

Também Gonçalo Rodriguez Cabreira valorizou, na sua obra, as propriedades curativas do antimónio e de muitos outros remédios de origem mineral com base no mercúrio, antimónio, enxofre, vitríolo, tártaro e outros elementos, sem deixar de ser profundamente fiel às doutrinas de Galeno.

Por sua vez, Manoel de Azevedo na sua Correcção de Abusos Introduzidos contra o Verdadeiro Methodo da Medicina dedica quase todo o Tratado Primeiro aos "grandes danos e irremediáveis males e mortes que causam as demasiadas sangrias», em cuja prática se baseava em larga escala a terapêutica galénica, como forma privilegiada de se recuperar o equilíbrio perdido dos humores; e exalta, em contrapartida os grandes e quase miraculosos proveitos que obram as purgas: «por não purgarem, e muito sangrarem aos enfermos, perecem muitos» (ref. 12, Trat. II, 52); "as sangrias demasiadas causaō muitas e grandes enfermidades e mortes" e "são reprovadas por todos os grandes autores") (ref. 12, Trat. 1, 2-8). nem por isso se afasta da teoria dos humores de Galeno, defendendo que as purgas "devem ser conformes aos humores que peccão" (ref. 12, Trat. 1, 54). E todo o seu tratado se centra, do ponto de vista anatómico, no Fígado, tido como «a officina do sangue e o princípio de todas as veas do corpo" (ref. 12, Trat. II, 33).

1.2 - Só na segunda metade do século XVII, a química médica em Portugal se abre claramente a teorias não-galénicas, nomeadamente às teorias de Paracelso e dos iatroquímicos em geral, em particular pelas mãos do genovês Carlo António Paggi e de João Curvo de Semmedo.

Nomeado, em 1656, proconsul da República de Génova em Lisboa, Carlo António Paggi rapidamente se incorporou no grémio literário de maior prestígio que então florescia em Lisboa, a seiscentista Academia dos Generosos, a partir da qual pugnou, em tom vigoroso e até polémico, pela renovação da Medicina portuguesa. Em 1664, antes de voltar para a sua pátria, publicou, em Lisboa, o Enchiridon medico iatro-chymico (15) onde se opøe frontalmente à teoria dos humores de Galeno e desenvolvendo a teoria paracelsista dos três principios, «illa tria sal, sulphurus et mercurius (...) unde illud vulgum salia salibus curantur" (ref, 15, pg. 376). E faz-se arauto dos mais famosos autores da escola iatroquímica, nomeadamente Crollius e Hartmann, bem como dos remédios purgativos «de invenção muito recente, elaborados com a maior perícia pelos químicos, e completamente ignorados pelos antigos, mas com razão dignos de ser contados entre os milagres da natureza, preparados à base do antimónio, mercúrio, enxofre, vitríolo, tártaro e outros elementos da mesma espécie» (ref. 15, pg 189). Dos «remédios chimicos» que refere constam o "specifium purgans Paracelsi» (ref. 15, pp. 222, 380), o «corallinum Paracelsi» (ref. 15, pg. 380), o "panchymagogon Quercetani» (ref. 15, pg. 289), etc... (16).

Nascido em 1535, J. Curvo de Semmedo tornou-se publicamente conhecido em $1680 \mathrm{com}$ a publicação do Tratado da Peste (17). Anos depois, publicaria Polhyanthea Medicinal (18), um memorial de vários simples, um manifesto sobre as sangrias, um tratado sobre o ouro diaforético e várias observaçōes médicas (19). Em todos estes seus tratados, com particular relevo para a Polyanthea Medicinal, Semmedo mostra conhecer bem a mais moderna bibliografia e prática da medicina e da química. Neles elogia a eficácia dos remédios de antimónio e referencia entusiasticamente as doutrinas de Paracelso, Van-Helmont, Poterius, Boyle, Descartes, Hoffman, N. Lémery, Libavius, Silvius, Matthiolo, Crollius, J. Baptista Porta e muitos outros. Defendendo o entendimento dos Modernos, ele aduz experiências de sua própria lavra, com as quais procura mostrar como as explicaçōes dos Antigos, em contraposição às dos Modernos, não deram explicação cabal de muitos e variados fenómenos (ref. 18, pg. 719).

\section{O experimentalismo em Portugal setecentista e a química das Farmacopeias}

2.1 - Com o alvorecer do século XVIII, assiste-se, em Portugal, ao fervilhar de um interesse crescente pela filosofia e prática do empirismo racional que enformava a nova ciência além fronteiras. Em Lisboa, na Casa dos Ericeiras, reúne-se regularmente um grupo de eruditos portugueses com diplomatas, sacerdotes e homens de ciência estrangeiros, versando nas suas liçðes e discussð̋es, inváriavelmente, temas de Física e Matemática, à luz da logica moderna, explicitamente contrastada com a dos antigos. Esse grupo ficou conhecido pela Academia dos Discretos. Nos seus trabalhos participaram, entre outros, sobre temas da nova ciência, Jussieu, da Academia de Ciências da Paris, o abade de Estress e o abade Mornay (ref. 20, pp. 105-107).

Em 1708, Contador Argote, «deixada a derrota que em filosofia tem por luz e guia principal a autoridaden, mostrava-se acérrimo defensor daquela «doutrina que os filosofos modernos entraram a abraçar e que, segundo a boa crítica, dá nesta matéria o primeiro lugar à razão e à experiência" (21). Poucos anos depois, em 1712, Rafael Bluteau em o Vocabulário Portuguez e Latino (22), divulga, em língua portuguesa, Kepler, Mariotte, Boyle, Gassendi, Descartes, Huygens, Galileu, Cassini, Borelli, etc., presidindo à elaboração da sua obra o desejo de convencer os seus leitores - como textualmente o declaria mais tarde em Prosas Portuguesas - de que «a logica do intelecto especulativo é estéril, porque meras especulaçôes não produzem fruto" (ref. 23, Tom. I, pg. 107), chamando a atenção dos mesmos para obras como o Colégio Experimental de Estúrnio, as Efemérides dos Curiosos da Natureza 
da Academia de Leipzig, as Memórias da Academia de Ciências de Paris, o Journal des Sçavants, etc.

Em 1721, funda-se em Lisboa a Academia Portuguesa de Historia que desde logo manteve grandes contactos com idênticas associaçōes culturais estrangeiras, no sentido duma renovação cultural (ref. 20, pp. 168ss.). De salientar os contactos que com ela manteve Jacob de Castro Sarmento, refugiado em Londres, em insistência contínua de que "pelo tempo adiante a instituição das histórias desse também as mãos às Artes e Sciencias" de modo que as ciências naturais chegassem à perfeição e beleza em que as achavam os estrangeiros (24). O mesmo Jacob Sarmento, em 1731, mantinha estreitos contactos com a Universidade de Coimbra, enviando-lhe um microscópio para uso de observaçōes botânicas e anatómicas, num esforço de levar os mestres que nela ensinavam a rumar por novos caminhos (25). Não contente com esses redobrados contactos, e desejoso de ver o empirismo racional expandir-se em Portugal, traduziu para português a obra de Pedro Shaw Proposiçoens para Imprimir as Obras Philosophicas de Francisco Baconio (26) e escreveu um pequeno tratado subordinado ao título Theorica Verdadeira das Marés, conforme a Filosofia do incomparável Cavalhero Isaac Newton (27).

Em 1722, cria-se, em Lisboa, o Observatório de Santo Antão, sob a acção dos Jesuítas João Baptista Carbone (1694-1750) e Domingos Capassi (1694-1736) que muito contribuiu para o renascimento das matemáticas entre os Jesuitas deste reino (ref. 20, pg. 118); Luis Baden, filosofo inglês, repete, em Lisboa, em 1725, as experiências de Torricelli e explica a teoria da luz e das cores por meio de prismas, pesa o ar e ilustra experimentalmente os princípios fundamentais da mecânica e da optica, seguindo de perto as doutrinas de Boyle e Newton, num curso de Filosofia Experimental que se deveria prolongar por trinta sessð̄es (ref. 20 , pp. 118-120). Nos primeiros anos da década de trinta, as obras do espanhol frei Bento Jerónimo Feijoo, nomeadamente o Teatro Crítico (28) e as Cartas Eruditas (29) suscitaram grande interesse, «correndo, com largueza maior ou menor, umas vezes na integra, outras em simples parcelas, entre o escol da nossa gente culta», nem faltando sequer resumos para lhes divulgar o conteúdo. Frei Pedro Esteves, da Ordem Terceira da Penitência, no Curso que ministrava no Convento de Jesus, servia-se, na cátedra, dessas obras, segundo testemunho de frei Manuel do Cenáculo; Francisco Botelho de Morais faz-lhes a mais lisonjeira referência no seu poema $E l$ Alfonso, o la Fundacion del Reyno de Portugal; D. Manuel Caetano de Sousa cita-o frequentemente na sua Expeditio Hispanica Sancti Iacobi Maioris (ref. 30, pp. 8-9); e, em 1746, em $O$ Verdadeiro Método de Estudar, confessará Luis Verney: «eu não tenho o Feijóo diante dos olhos porque haverá mais de doze anos que o lin (ref. 31, vol. 3, pg. 161).

No Hospital Real de Todos-os-Santos, em Lisboa, em 1732 , o anatomista italiano B. Santucci substitui Monterara y Roca, compulsivamente aposentado, e logo se torna notado pelo esforço que fez no sentido de substituir o ensino especulativo por um ensino experimental (32). pela mesma altura, D. Luis da Cunha e Alexandre de Gusmão, tecem longas criticas à mentalidade atrofiante das Ordens Religiosas que acusam de se acharem excessivamente fechadas numa Escolástica por demais especulativa, pugnando simultaneamente pela coarctação da acção nefasta da Inquisição e pela restituição aos judeus da liberdade de consciência (ref. 20, pp. 121-123). De Alexandre de Gusmão pode escrever M. de Araújo: «conservou sempre uma sábia propensão para a mecânica, em que não só observava seus efeitos sempre admiráveis, mas ajudado das leis do movimento, em que teve um estudo mui profundo, observando na diversidade de instrumentos as experiências, procurava adiantar com sólidas e novas reflexðes a inteira inteligência das suas causas», "deixando-nos de sua douta aplicação três livros em que examina eruditamente o sistema do grande Newton» (33).

Todo este crescente interesse por uma nova ciência fundada no empirismo racional institucionaliza-se, se assim o podemos dizer, nos anos quarenta do século XVIII, no ensino ministrado nas Escolas da Congregação do Oratório que por provisão de 1708 (anulada em 17 de Outubro de 1724 , mas logo reposta em 25 de Janeiro de 1725) gozavam de privilégios idênticos aos concedidos às Escolas da Companhia de Jesus. Seguindo de perto o curso filosófico do oratoriano espanhol Vicente Tosca (34) e contando com mestres como João Baptista autor da Philosophia Aristotelica Restituta (35), o ensino nas Escolas oratorianas é um ensino bem enformado das novas orientaçðes científicas, com referências claras às doutrinas de Galileu, Newton, Huygens, Halley, Boyle, Locke, Descartes e Gassendi, e totalmente empenhado numa reformulação da Escolástica em que se salvaguarde a essência do aristotelismo e os imperativos da ortodoxia religiosa.

$\mathrm{O}$ estudo pormenorizado de tal interesse esvazia em grande parte algumas análises de L. Verney no Verdadeiro Método de Estudar e a análise de $O$ Compêndio Histórico do Estado da Universidade de Coimbra, 1771 (36), remetendo umas e outras exclusivamente para o caso do ensino oficial que continuava a ser ministrado na Universidade, realmente conservador, embora também já eivado, aqui e além, por vozes discordantes. De facto, não se vê como em 1746, Verney pudesse escrever, sem alguma falta de objectividade, que depois dos meados do século XVI, o ensino em Portugal votava aos desprezo «todos os estudos estrangeiros, e com tal empenho, como se fossem maus costumes ou coisas muito nocivas» (ref. 31 , vol. 3 , pg. 18 ), como se não compreende como, em 1771, o Compêndio Histórico do Estado da Universidade podia dar como provado que a partir dos meados do século XVI, «as Artes e as Ciências haviam sido desterradas destes Reinos e seus dominios, deixando a Monarquia Portuguesa nas trevas da ignorância” (ref. $36, \mathrm{pg}$. IX), tudo atribuindo, com manifesta parcialidade, à acção nefasta dos Jesuítas. Compreende-se facilmente, como o testemunharia mais tarde João Pedro Ribeiro, que se tenha achado «em grande tortura o colaborador do Compêndio Histórico para satisfazer a tarefa de que fora incumbido de imputar aos Jesuítas também a corrupção entre nós da Chimica» (37). E que desde os inícios do século XVIII, a química que se praticava em Portugal, embora com apreciáveis atrasos, acertara já seus passos pelas práticas e teorias químicas de além fronteiras; faltava-lhe apenas afirmar-se e estabelecer-se como disciplina autónoma e libertar-se definitivamente da porção de galenismo que sobrevivia, no ensino e na prática farmacêutica, de mãos dadas com uma prática iatroquímica, em pacífica convivência e aliança, sem conflitos de maior. A Polyanthea Medicinal de J. Curvo de Semmedo a que já fizemos referência (18), cuja primeira edição data de 1697 , é muito clara a esse respeito, como o são a Pharmacopea Lusitana de D. Caetano de Santo António (38), em 1704 e 1711, o Apia- 
rium Medico-Chymicum de Fonseca Henriques (39), em 1711, e, sobretudo, o Thesouro Apollíneo, em 1714, e a Pharmacopea Ulissiponense, em 1716, de Joam Vigier (40-41), e ainda a Pharmacopea Tubalense de Rodrigues Coelho (42), em 1735.

\section{2 - Para Curvo Semmedo, a «chymica he uma Arte} que sabe abrir ou resolver todos os corpos compostos, purificando-os, para que os remédios que delles se fizerem, tenhaõ mayor virtude, e obrem com mayor efficacia» (ref. 18, pg. 693). "Seu fim interno é abrir ou resolver os corpos; seu fim externo, aperfeiçoar ou transmutar os metais menos nobres em outros mais nobres" (ref. 18, pg. 693). «Não basta ao médico ser médico; é necessário que seja também químico que só assim terá um grande partido para vencer as enfermidades rebeldes, pois a química the ensina a purificar os medicamentos. Ela é para o Médico o que são as armas para um soldado, o leme para um piloto, e as tintas para um pintor» (ref. 18, pg. 693). "Sem a química, é a Medicina um corpo morto, incapaz de especulação e de prática, e quem a desprezar (pelo trabalho que custa a aprender) perca as esperanças de curar doenças difficultosas" (ref. 18, pg. 695).

Aos remédios galénicos contrapðe Semmedo os remédios químicos que «em pouca quantidade, obraő sem enjoo, com mayor efficacia, com grande promptidão e com muita brandura» (ref. 18, pg. 694). E na química tem o médico a verdadeira fonte do saber como curar as doenças que procedem dos humores, do maleficio dos doces para os febricitantes, da necessidade dos gordos comerem cousas salgadas, do carácter mortífero da mordedura da víbora, da acção da quina-quina na cura das febres intermitentes, da mudança da cor do sangue exposto ao ar ácido, da acção do azougue, do mercúrio doce, da frescura de cal virgem em água, da virtude do ópio, da má digestão das coisas gordas no estomago, etc., etc... (ref. 18, Trat. III, cp. I, parágrafos 10 a 33 ).

As interpretaçð̃es de base química que dá para todos estes fenómenos, como já atrás o dissemos, assentam no entendimento dos Modernos, com particular realce para a circulação do sangue que os Doutores modernos «vieraō a descobrir no ano de 1628 e acharaðo ser cousa tão clara como a luz do sol» (ref. 18, pg. 699); a doutrina dos três princípios que por indústria da química se tem sabido, ao contrário do que pensavam os antigos, "que qualquer corpo terrestre consta de sal, enxofre e azougue" (ref. 18, pp. 718-719); e ainda uma certa concepção atomista da matéria; «ao contrário do que pensavam os Antigos para quem o pábulo do fogo era só a lenha, entendem os Modernos que este é também formado por átomos ácido-nitro-aéreos que andam espalhados pelo ar» (ref, 18, pg. 719).

2.3 - A primeira edição da Pharmacopea Lusitana de D. Caetano de Santo António, publicada no mesmo ano em que Curvo de Semmedo publicava a segunda edição da sua Polyanthea Medicinal, cinge-se apenas à farmácia galénica, sem qualquer referência à farmácia química; porém, sete anos depois, na segunda edição, (Lisboa, 1711), já afirma incluir «o método prático de compor os medicamentos na forma galénica e química» (ref. 38b, Subtítulo). para o seu autor, vindo da Botica do Mosteiro de Santa Cruz, em Coimbra, para a de S. Vicente de Fora, em Lisboa, a química confunde-se com a Pharmacia, tida como a warte de que se vale a Medicina curativa para escolher os medicamen- tos, preparar os simplices, proporcionar os compostos e extrair os espíritos" (ref. $38 \mathrm{~b}$, Proémio). Outo tanto se verifica com o Apiarium Medico-Chymicum de Fonseca Henriques, publicado no mesmo ano de 1711 , em Lisboa, confessadamente galénico no seu conteúdo, mas aberto às doutrinas dos modernos, nomeadamente a doutrina da circulação do sangue, «totalmente ignorada por Galeno, mas que os modernos não podem minimamente ignorar» (ref. 39, pg. 4).

2.4 - Na segunda década do século XVIII, com Joam Vigier, continuado, vinte anos depois, ao pé da letra e com a necessária actualização imposta pelo tempo, por Rodrigues Coelho, a prática iatroquímica impðe-se como prática corrente em Portugal.

Em o Thesouro Apollíneo, Joam Vigier, interessado por "todo o género de medicinas simples e chimicas" e «sempre curiosos dos melhores livros e Authores modernos" (ref. 40, Apresentação de Joam Gomes da Sylveira), propøe-se "descrever remédios simplices, e compostos de huma e outra doutrina, tanto galénica como spagírica" de que se serve o galénico para as suas infusðes, destilaçð̃es, decoctos, electuários e pós, como o Alchimista para a extracção de seus saes fixos e voláteis (ref. 40, Prólogo). E fá-lo com «capitulação sucinta deduzida da Filosofia de Carthesio, sem desprezar os preceitos de Galeno» (ref. 40, Aprovação de D. Cypriano de Pinna).

Joam Vigier pōe de lado, expressamente, a opinião atribuída a Hipócrates de que os purgativos fazem sua acção atraindo a si o humor que lhes é semelhante (ref. 40 , pg. 20); e de seu receituário fazem parte a bebida febrifuga de Crollius (ref. 40, pg. 140), o antihectico de Poterius (ref. 40, pg. 151), a água antiepiléptica e o elixir vitae de Quercetano (ref. 40, pg. 208), a tintura cephalica de Senerti (ref. 40, pg. 200), a água melancólica de N. Lémery (ref. 40 , pg. 218) e outras variadas perparaçōes de muitos outros filosofos químicos modernos.

Em 1716, na Pharmacopea Ulyssiponense Galenica e Chimica, Joam Vigier expøe brevemente os princípios da química Farmacêutica (ref. 41, pp 281-334) e trata das virtudes dos remédios químicos e das doses em que se devem dar, seguindo os ensinamentos do Curso de Química (44) e da Farmacopea Universal (45) de N. Lémery (ref. 41, pp 335-390), terminando com um tratado das virtudes e descrições de diversas plantas e partes de animais do Brasil e outras partes da América e do Oriente, tiradas de Guilherme Pison, Monardo, Clusius, A. Costa e outros (ref. 41, pp. 391-446).

A Química é apresentada por ele como uma das duas partes da Farmácia (a Farmácia Galénica e a Farmácia Química) que por sua vez é apresentada como a terceira parte da Medicina curativa, em contraposição com a medicina diathêutica e a medicina cirúrgica (ref. 41, pp. 1-2). Integrada na Medicina, a Química é tratada como uma anatomia, a anatomia dos mixtos, a arte que nos ensina a analisar as substâncias úteis e inúteis de cada mixto, num trabalho de separação e junção apropriadamente chamado, numa base etimologica, de arte espagirica (ref. 41 , pp. 281-282). Todo este trabalho de separação e junção das substâncias de cada mixto se desenrola tendo por quadro de fundo a doutrina dos cinco corpos simples dos químicos farmacêuticos do Jardin du Roi (Paris), Etienne de Clave, N. Lémery, N. Lefévre, Glaser e outros mais, que aos três princípios espagíricos de Paracelso haviam juntado a terra e a água, considerando todas as coisas constitui- 
das por três princípios activos (o espírito ou mercúrio, o bleo ou enxofre, e o sal) e por dois princípios passivos (a água ou phlegma e a terra ou caput mortuum) (ref. 41. pp. 283-285).

Para conseguir o seu objectivo, o químico dispõe de várias técnicas laboratoriais baseadas na tecnologia do fogo. A química é pyrotechnia. Vigier descreve com pormenor os aparelhos utilizados para esse fim, incluindo no seu Tratado estampas elucidativas dos mesmos juntamente com Tabelas dos principais caracteres químicos (ref. 41, pp. 294-297). As preparaçōes químicas que apresenta são também elas, na sua generalidade, as da Farmacopea Universal de N. Lémery, preparaçōes com base no estanho, antimónio e mercúrio, para além da água forte, a água régia, e vários óleos (ref. 41 , pp. 300-335).

\section{5 - A Farmacopea Tubalense Chimico-Galenica de} Manoel Rodrigues Coelho repete textualmente as consideraçōes de Joam Vigier sobre a definiçâo, origens, princípios, operaçð̃es e aparelhos da química (ref. 42, pp. 1-4, 886-898). E as composiçðes químicas de que se ocupa toda a Segunda Parte da obra são «composiçōes selectas, tanto dos Antigos como dos Modernos", de que se indica, para cada uma, a respectiva fonte. A maior parte delas são receituários da Farmacopea Universal e do Curso de Química de N. Lémery (ref, 42, pp. 353-886). São, todavia, referenciadas também, e repetidamente, a maioria das Farmacopeas então conhecidas, nomeadamente, a Farmacopea Schroder-Hoffman, a Farmacopea Regia, a Farmacopea Augustana Renovada, a Farmacopea Bateana, a Farmacopea Regia Galenica, a Farmacopea Dogmatica, a Farmacopea Extemporanea, a Farmacopea de Nurimberga, a Farmacopea Spagyrica, a Farmacopea de Edimburgo e a Farmacopea Londrina. Referenciados são, também, o Lexicon-Chymico-Pharmaceutico e a Chymica Experimental de Jungken, a Mantissa Spagyrica de Zwelfero, a Palestra Farmaceutica de Palacios, a Collectânea Chymica Leydenense, a Pharmacia Medico-Physica de Lemortio, o Thesouro Farmaceutico de Hoffman, a Biblioteca Pharmaceutica-Medica de Manget, e diversas obras do enciclopédico espanhol Francisco Ribera. As duas primeiras partes da Farmacopea Tubalense seriam completadas, alguns anos depois, com uma terceira parte em que o autor actualizaria o Diccionário Pharmaceutico Medico que integrava a Primeira Parte (Trat. I, cp. XXV) e, sobretudo, ao longo de mais de 200 páginas, apresentaria "composições diversas e exquisitas» referidas na vasta obra de Francisco Ribera (ref. 42, pp. 62-283), e ainda dois tratados de segredos médicos e cirúrgicos para remédios de muitas enfermidades (ref. 42, pp. 284-559); e um Discurso Phisico-Medico sobre as excelências da quina-quina, contendo 33 reflexð̄es sobre as suas diferentes preparaçð̄es e usos.

Repetindo Joam Vigier e Francisco de Ribera, a Farmácia Química de Rodrigues Coelho mantém-se à margem e ignora por completo a Historologia Médica de José Rodrigues de Abreu, publicada dois anos antes, em Lisboa (43), fundada e estabelecida em práticas e teorias mais consentâneas com as teorias e práticas químicas que lá fora imperavam já no dominio da ciência química - a química flogística do sistema stahliano. Também em Portugal, a farmácia galénica tinha seus dias contados.

\section{REFERENCIAS:}

1 - Sebastião do Couto, Commentaria Collegii Conimbricensis in Universam Dialecticam Aristotelis Stagyritae, Coimbra, Didacum Gomez Loureiro, 1606.

2 - Francisco Soares, Cursus Philosophicus, Coimbra, Typ. Pauli Craesbeeck, 1651

3 - António Cordeyro, Cursus Philosophicus Conimbricensis, Ulyssipone, Officina Regia Deslandesiana, 1714.

4 - Joåo Bravo Chamisso, De Medendis Corporis Malis per Manualem Operationem, Conimbricae, Typ. Emmanuel de Araújo, 1605 .

5 - Hieronymo Nunio Ramirez, Commentaria in Librum Galeni: De ratione curandi per sanguine missione, Lisboa, Officina Petri Craesbeeck, 1608 .

6 - Gonçalo Rodrigues Cabreira, Compêndio de muitos e Vários Remédios, de Cirurgia, e outras cousas curiosas, Lisboa, Off. António Alvres, 1611.

7 - André António de Castro, De Febrium Curatione Lib. 3; De simplicium medicamentorum Lib. 2; De qualitatibus alimentorum quae humani corporis nutrotioni stant apta Tract. 10, Villa Viçosa, Typ. Emmanuelis Carvalho, 1636.

8 - Duarte Madeira Arraiz, Methodo de Conhecer e Curar o Morbo Gallico, Lisboa, Antonio Alvarez Impressor del Rey, 1642.

9 - Eduardo Madeira Arrais, Novae Philosophiae et Medicinae de Qualitatibus Occultis a nemine unquam excultae, Lisboa, Typ. Emmanuel Gomes de Carvalho, 1650.

10 - Antonio da Cruz, Recompilaçam de Cirurgia, Lisboa, Off. Jorge Rodrigues, 1601.

11 - Gabriel Grisley, Desenganos para a Medicina ou Botica para todo Pay de Familias, Coimbra, Officina Thomé Carvalho Impressor da Universidade, 1656.

12 - Manoel de Azevedo, Correcção e Abusos contra o Verdadeiro Methodo de Medicina, Lisboa Officina Diogo Soares de Bulhoens, 1668 .

13 - Thome Rodrigues da Veiga, Practica Medica, Lisboa, Typ. Joannis A. Costa Senioris, 1668.

14 - (a) Walter Pagel, William Harvey's Biological Ideas: Selected Aspects and Historical Background, New York, S. Karger, 1967, pp. 94-102; (b) Hervé Baudry, Estevão Rodrigues de Castro et la question du Parecelsisme au Portugal, Rev. Univ. Aveiro, Letras, 1985, pp. 367-389.

15 - Carlo António Paggi, Enchiridon Medico-iatro-chymico, Lisboa, 1664 .

16 - (a) Giacinto Manupella, Camoniana Italica. Subsídios Bibliográficos, Coimbra, 1972; (b) Joaquim Araújo, Intorno al Genovese Carlo Antonio Paggi, Génova, 1889; (c) José Costa Miranda, Carlo António Paggi, Tradutor de Camōes: a sua presença na seiscentista Academia dos Generosos de Lisboa, Rev. Biblioteca Nacional, vol. 1 (1981), pp. 253-272.

17 - João Curvo de Semmedo, Tratado da Peste, Lisboa, Off. João Galram, 1680.

18 - João Curvo de Semmedo, Polyanthea Medicinal. Notícias Galénicas e Chymicas, Ediçōes em vida do autor (a) Lisboa, Officina Miguel Deslandes, 1697; (b) Lisboa, Officina Antonio Pedroso Galram, 1704; (c) Lisboa, Officina Antonio Pedroso Galram, 1716.

Nota: no presente trabalho, referenciamos o texto da edição de 1716.

19 - João Curvo de Semmedo, (a) Observações Médicas Doutrinais, Lisboa, António Pedroso Galram, 1727; (b) Memória dos Remédios Exquisitos, (sem local de impressāo); (c) Manifesto feito aos amantes da saúde $e$ atentos às suas consciências, Lisboa, Valentim da Costa Deslandes, 1706; (d) Tratado do ouro diaforético, (sem local de impressão); (e) Manifesto em que se mostra com gravissimos Doutores que se podem dar purgas estando os humores crus, (sem local de impressão).

20 - José Sebastião da Silva Dias, Portugal e a Cultura Europeia - Secs. XVI e XVIII, Coimbra, Coimbra Editora, 1953.

21 - D. Tomás Caetano do Bem, Memórias Históricas e Cronológicas da Sagrada Religiâo dos Clérigos Regulares em Portugal e suas Conquistas na India Oriental Tom. II, Lisboa, Régia Officina, 1794, pg. 201.

22 - Rafael Bluteau, Vocabulário Portuguez e Latino, Coimbra, Collegio das Artes, 1712-1728.

23 - Rafael Bluteau, Prosas Portuguesas, Lisboa Occidental, Off. Joseph António da Sylva, 1728.

24 - Livro 3 . $^{\circ}$ do Registo de Cartas da Academia Real da História Portuguesa, fl. $158 \mathrm{v}$.

25 - Herculano Amorim Ferreira, Relações Cientificas entre Portugal e a Grã-Bretanha, Lisboa, Academia das Ciências, 1943, pp. $12-13$.

26 - Pedro Shaw, Proposiçoens para Imprimir as Obras Philosophicas de Francisco Baconio, Londres, 1731.

27 - Jacob de Castro Sarmento, Theorica Verdadeira das Marés, conforme a Filosofia do Incomparavel Cavalhero Isaac Newton, Londres, 1737. 
28 - Benedito Jeronimo Feijóo, Theatro Critico Universal, Madrid, Francisco Hierro, 1726-1740.

29 - Benedito Feijóo, Cartas Eruditas y Curiosas, Madrid, Francisco Hierro, 1741-1760.

30 - José Sebastião da Silva Dias, Seiscentismo e Renovação em Portugal no século XVIII - Estudo de um Processo Inquisitorial, Coimbra, Universidade, Faculdade de Letras, 1961.

31 - Luis António Verney, Verdadeiro Méthodo de Estudar para ser útil à República e à Igreja, proprocionado ao estado e necessidade de Portugal, Valensa, Antonio Balle, 1746.

Nota: no presente trabalho, as referências a esta obra correspondem à edição Sá da Costa (Lisboa, 1949-52).

32 - Joaquim O.A. Pires de Lima, Bernardo Santucci e a nomenclatura anatómica Portuguesa, in Estudos Italianos em Portugal, vol. 1 (1940), pp. 310-323.

33 - M. de Araújo, Elogio de Alexandre de Gusmão, pp. 4 e 17, cit. in ref. 20, pg. 123.

34 - Tomás Vicente Tosca, Compendium Philosophicum Praecipuas Philosophiae Partes Complectens, Valência, 1721.

35 - João Baptista, Philosophia Aristotelica Restituta et Illustrata qua experimentis qua ratiociniis nuper inventis, Lisboa, 1748.

36 - Compêndio Histórico do Estado da Universidade de Coimbra no tempo da invasão dos Denominados Jesuitas..., Lisboa, Real Officina Typográfica, 1771.
37 - João Pedro Ribeiro, Observações Históricas, Lisboa, Academia Real das Sciencias, 1798.

38 - D. Caetano de Santo António, (a) - Pharmacopea Lusitana, methodo pratico de preparar os medicamentos na forma galenica, com todas as receitas mais usuais, Coimbra, Off. João Antunes, 1704; (b) Pharmacopea Lusitana Reformada, Lisboa, Real Mosteyro de S. Vicente de Fora, 1711.

39 - Francisco a Fonseca Henriquez, Apiarium Medico-Chymicum, Amestelodami, Officina Michaelis Diaz, 1711.

40 - Joam Vigier, Thesouro Apollineo, Galénico, Chimico, Chirurgico, Pharmaceutico, Lisboa, Officina Real Deslandesiana, 1714. 41 - Joam Vigier, Pharmacopea Ulyssiponense, Galenica e Chimica que contem os Principos, Definiçoens e Termos Gerais de huma e outra Pharmácia, Lisboa, Pascoal da Sylva, 1716.

42 - Manoel Rodrigues Coelho, Pharmacopea Tubalense Chemico-Galenica, Lisboa Occidental, Officina de Antonio de Sousa Sylva, 1735.

43 - Joseph Rodrigues de Abreu, Historologia Médica, Fundada e Estabelecida nos Principios de George Ernesto Stahl, Lisboa Occidental, Officina de Musica, 1733.

44 - Nicholas Lémery, Cours de Chimie, Paris, 1675.

45 - Nicholas Lémery, Pharmacopée Universelle, Paris, 1697.

\title{
Passatempo
}

\author{
Problema $n .^{0} 2$ *
}

Quais as palavras relacionadas com química que se encontram escondidas no quadro seguinte?

As palavras podem estar escritas em ambos os sentidos da horizontal, vertical e diagonais.

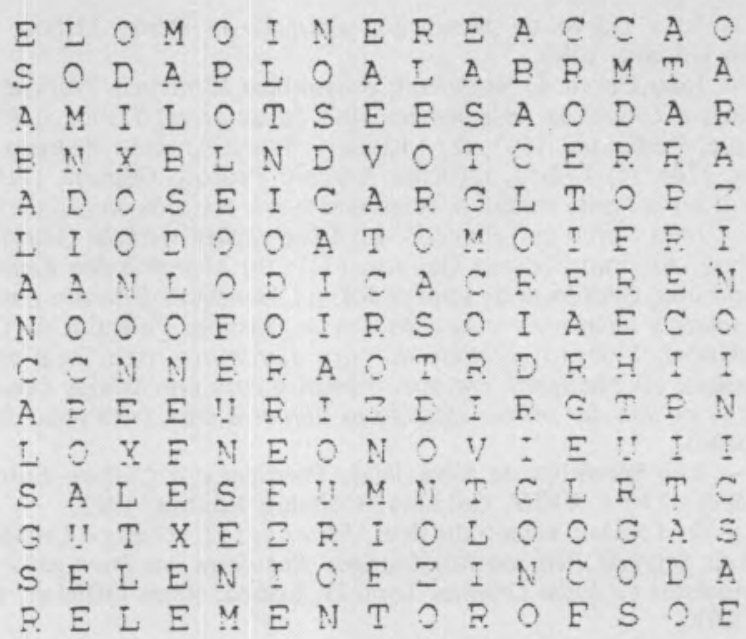

Soluçð̃es do problema $n .^{\circ} 1$

Como de certeza descobriu, basta substituir os números pelos símbolos dos elementos com esses números atómicos para encontrar a frase: «Bom dia caro sócio. Nas nossas notícias, vamos agora incluir esta rubrica sobre cifras. Esperamos a sua colaboração!»

* Enviem-nos a solução deste passatempo. Entre as respostas correctas será sorteada a aguarela reproduzida na contra-capa deste Boletim! 